\title{
Multiple Sclerosis and Chlamydia
}

\author{
Jose Artur Medina
}

Biochemical Physiopathology Medicine Faculty of University of São Paulo, Laboratory of Biochemical and Biophysical Butantan Institute, Brazil.

*Corresponding Author: José Artur Medina, Pediatrician, MD degree, Doctoral student in Biochemical Physiopathology Medicine Faculty of University of São Paulo, Laboratory of Biochemical and Biophysical Butantan Institute, Brazil.

\section{Received Date: 11 August 2021 | Accepted Date: 29 October 2021 | Published Date: 09 November 2021}

Citation: Jose A Medina. (2021). Multiple Sclerosis and Chlamydia. International Journal of Clinical Case Reports and Reviews. 9(1); DOI:10.31579/2690-4861/163

Copyright: (c) 2021 Jose Artur Medina, This is an open-access article distributed under the terms of the Creative Commons Attribution License, which permits unrestricted use, distribution, and reproduction in any medium, provided the original author and source are credited.

Dear Editor, In 2002 Hawkes realized that epidemiologically multiple sclerosis (MS) behaves like an STD [1]. Although the epidemiological similarity between the two diseases is true, this thesis was not discussed extensively, perhaps because it implied that some children might have been victims of abuse, which sounds false and potentially unfair. We believe that transverse myelitis and MS are the result of an infectious disease, eventually sexually transmitted by chlamydia/gonococcus, which is caused by a subclinical bacterial urethritis/inflamatory pelvic disease (IPD) among adults. In children it is the same disease but caused by common uropathogens/enterobacteria. Both UTI and MS are much more common in girls than in boys [2,3]. These UTIs would favor herpetic proliferation via toll-like receptors (TLRs), since the virus is endemic and always present, and it is not possible to eradicate it completely $[4,5,6]$. Herpes viral load is counteracted by interferon alpha 1 (IFN alpha-1), present in different cell types, from macrophages to lymphocytes passing through endothelia and fibroblasts. Interferon alpha 1, when interacting with its specific receptors, produces in the intracellular the action of antiviral RNAse and the inhibition of viral protein synthesis [7, 8]. TLR2/4 when stimulated by lipopolysaccharides (LPS) from bacteria reduce the production of IFN alpha increasing the viral load $[9,10,11]$. Viral proliferation can be stimulated via LPS, ie, pathogen-associated molecular protein (PAMP), which by stimulating inflammation, by interacting with TLR2/4, would reduce IFN-alpha1 and, consequently, increase viral load. On the other hand, the stimulation of these same receptors by fibronectin or hyaluronic acid, tissue "chunks", damage associated protein (DAMP), would increase the biosynthesis of IFNalpha1 reducing the viral load $[12,13]$. Herpes proliferation would favor the exteriorization of MHC type 2 complexes [14, 15, 16], which characterizes transverse myelitis and MS, favoring the chemotaxis of Th17 and Th1 CD4s. Intestinal parasites and dysbiosis - transmissible by water - produce chronic elevations of Th17 CD4 [17], which by itself reduce the blood-brain barrier [18]. Urine infections in childhood are caused by enterobacteria, [19] which are epidemiologically important agents, as they cause diarrhea [20] that occur anywhere in the world, although more frequent in the third world [21]. Transmissible through water, enterobacter are the main responsible for infant mortality in poor regions and among the elderly they determine longevity [22, 23, 24], are more prevalent than imagined and both positively affect rheumatoid factors $(25,26)$ and produce reactive arthritis $[27,28]$; when asked if there would be a cause/effect relationship between dysbiosis and rheumatic diseases, it is heard: "cross reaction" [29]. The choice of assigning an obscure origin to autoimmune diseases is to opt for the uncertain, since the positivity of the test is attributed to an obscure origin, to the detriment of what the test actually measured and in what clinical conditions the test is positive.

I ask: It would not be possible for enterobacteria, according to the magnitude of the intestinal dysbiosis that they produce, to increase the levels of Th17 and that - in the same individual - there is a subclinical urethritis/itu/IPD, whose magnitude would favor the inhibition of IFNalpha1 and consequently would favor the proliferation of herpes in the tissues previously affected? Could this unfortunate encounter be the cause of MS and transverse myelitis? Bacterial urethritis is often asymptomatic, elevating the same interleukins that MS, IL-8 and IL-18 [30, 31, 32, 33], in addition to Th17 and Th1 $[34,35]$. Outpatient treatment of a possible post coital cystitis, for example, would not eradicate bacterial vaginosis or chlamydia, making them potentially resistant, perpetuating the IPD/UTI insidiously $[36,37]$. The pathophysiology of transverse myelitis in MS could be explained as a result of neurodegeneration dependent on lymphocyte infiltration of Th17 and Th1, which when interacting with local type II MHC [38, 39, 40] would release IL-17A causing IL-6 and TNF alpha release with subsequent neurodegeneration, of course inflammatory and demyelinating [40]. The thesis proposed by Haewek explains absolutely all aspects of the disease, covering epidemiological, biochemical and clinical aspects such as the topography of the lesions, specifically lymphocytic infiltration, in MS. If this text is correct, the neurodegeneration of MS could be stopped through dewormers, antibiotics, beta glucan, probiotics and by far the most difficult: to avoid reinfection, since the health factors linked to intestinal dysbiosis persist, after all, they are linked to socio-economic aspects, which are difficult to change. After resolution of urethritis/cystitis/pyelonephritis/DIPA garlic capsules, perhaps via organo sulfur molecules, would favor the release of IFN-alpha1 and IFN-gamma [41, 42, 43]. The patients with increased levels of antinuclear autoantibodies would be infected with vaginosis bacterial, and receive diagnosis of lupus [44].

\section{References}

1. Hawkes C H. (2002). Is multiple sclerosis a sexually transmitted infection?. Journal of Neurology, Neurosurgery \& Psychiatry 73(4): 439-443. 
2. Harbo, Hanne F, Ralf Gold, and Mar Tintoré. (2013). Sex and gender issues in multiple sclerosis. Therapeutic advances in neurological disorders. 6(4): 237-248.

3. Barton Erik S, et al. (2007). Herpesvirus latency confers symbiotic protection from bacterial infection. Nature. 447(7142):326-329.

4. Finan R R, U Musharrafieh, and W Y Almawi. (2006). Detection of Chlamydia trachomatis and herpes simplex virus type 1 or 2 in cervical samples in human papilloma virus (HPV)-positive and HPV-negative women. Clinical microbiology and infection. 12(9):927-930.

5. Is there a cure for herpes? Current research and treatments.

6. Li Shi-fang, et al. (2018). Type I interferons: distinct biological activities and current applications for viral infection. Cellular Physiology and Biochemistry. 51(5):2377-2396.

7. Teijaro, John R. (2016). Type I interferons in viral control and immune regulation. Current opinion in virology. 16:31-40.

8. Liu $\mathrm{Yu}$, et al. (2014). TLR2 and TLR4 in autoimmune diseases: a comprehensive review. Clinical reviews in allergy \& immunology. 47(2):136-147.

9. Kawai, Taro, and Shizuo Akira. (2010). The role of patternrecognition receptors in innate immunity: update on Toll-like receptors. Nature immunology. 11(5): 373-384.

10. Estruch Montserrat, et al. (2013). CD14 and TLR4 mediate cytokine release promoted by electronegative LDL in monocytes. Atherosclerosis. 229(2):356-362.

11. Kurt-Jones, Evelyn A, et al. (2004). Herpes simplex virus 1 interaction with Toll-like receptor 2 contributes to lethal encephalitis. Proceedings of the National Academy of Sciences. 101(5):1315-1320.

12. Piccinini A M, and K S Midwood. (2010). "DAMPening inflammation by modulating TLR signalling." Mediators of inflammation 2010.

13. Zuo, Jianmin, and Martin Rowe. (2012). Herpesviruses placating the unwilling host: manipulation of the MHC class II antigen presentation pathway. Viruses 4(8): 1335-1353.

14. Wiertz, Emmanuel J, et al. (2007). Herpesvirus interference with major histo compatibility complex class II-restricted T-cell activation. Journal of virology. 81(9):4389-4396.

15. Deshpande, Shilpa P, Udayasankar Kumaraguru, and Barry T. Rouse. (2000). "Dual role of B cells in mediating innate and acquired immunity to herpes simplex virus infections." Cellular immunology. 202(2):79-87.

16. Liu, Fan, Hui-Bin Yin, and Chuan Su. (2008). "Th17 in the immunity against parasitic infection." Zhongguo ji sheng chong xue yu ji sheng chong bing $\mathrm{za}$ zhi= Chinese journal of parasitology \& parasitic diseases. 26(5):382-386.

17. Kebir, Hania, et al. (2007). Human TH 17 lymphocytes promote blood-brain barrier disruption and central nervous system inflammation. Nature medicine. 13(10):1173-1175.

18. Flores-Mireles, Ana L, et al. (2015). Urinary tract infections: epidemiology, mechanisms of infection and treatment options. Nature reviews microbiology. 13(5):269-284.

19. Amisano, Gabriella, et al. (2011). Diarrheagenic Escherichia coli in acute gastroenteritis in infants in North-West Italy. New Microbiologica. 34(1): 45-51.

20. Scallan, Elaine, et al. (2013). "Estimates of illnesses, hospitalizations and deaths caused by major bacterial enteric pathogens in young children in the United States." The Pediatric infectious disease journal. 32(3): 217-221.

21. Water, Sanitation and Hygiene | UN-Water.
22. Mara, Duncan, et al. (2010). "Sanitation and health." PLoS medicine. 7(11).

23. Paula Monteiro Gomides, Ana, et al. (2017). Parasites in rheumatoid arthritis: imminent threat or protective effect? Current rheumatology reviews. 13(2):80-85.

24. Ramos J A, F C Prado, and J R Valle. (1999). Atualização terapêutica. São Paulo.

25. Reactive arthritis-NHS.

26. Reactive Arthritis: Practice Essentials, Background, Pathophysiology.

27. Holm, Bettina E, et al. (2015). Species cross-reactivity of rheumatoid factors and implications for immunoassays. Scandinavian journal of clinical and laboratory investigation. 75(1):51-63.

28. Khadra Abbas, et al. (2006). Interleukin-8 levels in seminal plasma in chronic prostatitis/chronic pelvic pain syndrome and nonspecific urethritis. BJU international. 97(5):1043-1046.

29. Verma, Vivek, et al. (2016). Inflammasomes and their role in innate immunity of sexually transmitted infections. Frontiers in immunology. 7:540.

30. Lund, Brett T, et al. (2004). Increased CXCL8 (IL-8) expression in multiple sclerosis. Journal of neuroimmunology 155(12):161-171.

31. Losy J, and A. Niezgoda. (2001). IL-18 in patients with multiple sclerosis. Acta neurologica scandinavica. 104(3):171-173.

32. Quick, Marsha L, et al. (2013). Th1-Th17 cells contribute to the development of uropathogenic Escherichia coli-induced chronic pelvic pain. PloS one. 8(4):60987.

33. Prajeeth, Chittappen K, et al. (2017). Effectors of Th1 and Th17 cells act on astrocytes and augment their neuroinflammatory properties. Journal of neuro inflammation. 14(1):1-14.

34. Wanic-Kossowska M, et al. (2001). Acute and chronic urinary tract infections caused by Chlamydia trachomatis. International urology and nephrology. 32(3): 437-438.

35. Vaginal bacteria can trigger recurrent UTIs, study shows Washington University School of Medicine in St. Louis.

36. Hedegaard, Chris J, et al. (2008). T helper cell type 1 (Th1), Th2 and Th17 responses to myelin basic protein and disease activity in multiple sclerosis. Immunology. 125(2):161-169.

37. Kaskow, Belinda J, and Clare Baecher-Allan. (2018). Effector T cells in multiple sclerosis. Cold Spring Harbor perspectives in medicine 8(4): a029025.

38. Riedhammer, Christine, and Robert Weissert. (2015). Antigen presentation, autoantigens, and immune regulation in multiple sclerosis and other autoimmune diseases. Frontiers in immunology. 6:322.

39. Bhattacharyya, Mau, et al. (2007). Systemic production of IFN$\alpha$ by garlic (Allium sativum) in humans. Journal of Interferon \& Cytokine Research. 27(5):377-382.

40. Rouf, Razina, et al. (2020). Anti-viral potential of garlic (Allium sativum) and it's organosulfur compounds: a systematic update of pre-clinical and clinical data. Trends in food science \& technology.

41. Bakre, Adetolase A, Omolade A. Oladele, and Oluwaseun O. Esan. (2020). Garlic Enhances Cellular Immune Response Via Increased Secretion of IFN- $\gamma$-in Chickens. Alexandria Journal for Veterinary Sciences. 66(2).

42. Ginsburg, Katherine S, et al. (1992). Ureaplasma urealyticum and Mycoplasma hominis in women with systemic lupus erythematosus. Arthritis \& Rheumatism: Official Journal of the American College of Rheumatology. 35(4):429-433. 